\title{
ALÇAMENTO DAS VOGAIS POSTÔNICAS FINAIS /e/ E /o/ NAS CIDADES DE CURITIBA E LONDRINA
}

\author{
Larissa Natiele de Lima ${ }^{1}$
}

\section{RESUMO}

Essa pesquisa, ancorada nos pressupostos teórico-metodologicos da Sociolinguistica Variacionista, tem como foco o estudo da regra variável de alçamento das vogais média postônica final anterior /e/ (leite $\sim$ leiti) e posterior /o/ (terreno $\sim$ terrenu) no falar da região Leste (Curitiba) e região Norte (Londrina) do Paraná. Neste sentido, utilizamos dados coletados pela equipe do Atlas Linguístico do Brasil (ALiB, 1996) que foram recortados da fala de 12 participantes sendo 8 de Curitiba, região Leste do Paraná e 4 de Londrina, cidade da região Norte, interior paranaense. Esses dados foram estratificados pela equipe do Alib quanto à idade, sexo, localidade e, no caso da capital (Curitiba), quanto à escolaridade. Sendo assim, objetivamos investigar, na fala desses informantes, se os fatores linguísticos e/ou extralinguísticos influenciam no alçamento das referidas vogais e se, nas duas localidades, há o mesmo índice de alçamento dessas vogais e se esse fenômeno é governado pelos mesmos contextos nas duas localidades.

Palavras-chave: Vogais médias postônicas finais. ALiB. Sociolinguística.

\begin{abstract}
This research, anchored in the theoretical and methodological assumptions of Sociolinguistica variationist, focuses on the study of the uprising variable rule of middle vowels pos- tonic previous end / e / (leite $\sim$ leiti) and posterior / o / (terreno $\sim$ terrenu) in speaking of eastern region (Curitiba) and northern (Londrina) of Paraná. In this sense, we use data collected by the Atlas team Language of Brazil (Alib) that were cut speech of 12 participants and 8 Curitiba, east Paraná and 4 of Londrina, a city in the northern region, Paraná indoor. These data were stratified by the Alib team for age, sex, location and, in the case of capital (Curitiba) with regard to schooling. Therefore, we aimed to investigate the speech of informants, if the linguistic and / or extralinguistic factors influence the uprising of the members referred to and, in both locations, there is the same uprising index of these vowels and this phenomenon is governed by the same contexts in two locations.
\end{abstract}

Key words: Vowels average postônicas finals. Alib. Sociolinguistics.

\section{INTRODUÇÃO}

Desde os primórdios, o homem almejava a comunicação fazendo desenhos nas paredes das cavernas para expressar seus pensamentos. Além dessa origem, a linguagem também tem sua originalidade religiosa, com a construção da Torre de Babel, marcando

1 - Graduada em Letras - Português/Inglês, pela Universidade Estadual no Norte do Paraná; especialista em Língua Portuguesa, pela Universidade Estadual de Londrina; especialista em arte-educação e arteterapia no ambiente escolar, pela Faculdade de Tecnologia Vale do Ivaí; especialista em docência do ensino superior pela Faculdade de Tecnologia Vale do Ivaí. 


\section{SEMINÁRIO DE PESQUISA EM CIÊNCIAS HUMANAS - SEPECH \\ Humanidades, Estado e desafios didático-científicos \\ Londrina, 27 a 29 de julho de 2016}

a história sagrada pela falta de comunicação entre os trabalhadores, pois quanto mais alta ficava a torre, menos eles conseguiam se comunicar. Portando, a língua, derivação da linguagem, é a interação do trabalho social e histórico de uma sociedade. Cada grupo social tem sua forma de falar e se expressar, sendo assim, ela é a projeção das experiências de linguagem histórica (FIORIN, 2013).

Para Chauí (2009, p.173), Rousseau afirma que o homem se distingue pela língua, se ele não falar não sabemos sua origem. Dentro desse pensamento, constatamos que a língua é a identidade cultural do ser humano, fazendo com que ele se diferencie dos demais animais. A estudiosa também fala sobre a denominação de linguagem para Platão que

considerava que a linguagem pode ser um medicamento ou um remédio para o conhecimento, pois, pelo diálogo e pela comunicação, conseguimos descobrir nossa ignorância e aprender com os outros. Pode, porém, ser um veneno quando, pela sedução das palavras, nos faz aceitar, fascinados, o que vimos ou lemos, sem que indaguemos se tais palavras são verdadeiras ou falsas. Enfim, a linguagem pode ser cosmético, maquiagem ou máscara para dissimular ou ocultar a verdade sob as palavras. A linguagem pode ser conhecimentocomunicação, mas também pode ser encantamento-sedução.

No intuito de contribuir para que o preconceito linguístico diminua e em consequências disso às diferenças sejam respeitadas e re/conhecidas, este estudo tem como objetivo principal analisar o uso das vogais médias postônicas finais no falar de Curitiba e Londrina. Além disso, investigamos quais contextos linguísticos e extralinguísticos influenciam no uso dessas vogais; verificamos quais das duas vogais /e/ ou /o/ é mais suscetível ao alçamento na pauta postônica final; por fim, averiguamos se o alçamento ou a manutenção das duas vogais (média anterior/e/ e média posterior /o/) são semelhantes nas duas localidades investigadas.

Sendo assim, o presente artigo apresenta uma breve revisão sobre a Teoria da Variação; traz alguns estudos variacionistas que tratam das vogais postônicas átonas finais no falar brasileiro; apresenta a metodologia; a análise e discussão dos resultados e, por fim, apresentamos as considerações finais sobre o uso das vogais postônicas finas no falar das cidades de Curitiba e Londrina.

\section{TEORIA DA VARIAÇÃO}

Quando estudamos a variação linguística, percebemos que ela está constantemente presente em nosso vocabulário. Nessa perspectiva, Labov (1968) começou a estudar a natureza da linguagem humana considerando seu caráter social e a variabilidade dos fatos sociais.

Através dos estudos de Labov, Tarallo (2005), aborda o "caos" linguístico que se dá entre duas (ou mais) maneiras de dizer a mesma coisa podem ser denominados "variantes linguísticas". Para Tarallo tudo que a mente humana não consegue processar, causa desconforto. Se pensássemos em um falante ouvinte ideal em uma comunidade linguística homogênea, tal qual a proposta de Chomsky (1965), veríamos a variação linguística, a heterogeneidade das comunidades de fala com um caos linguística, mas a 


\section{SEMINÁRIO DE PESQUISA EM CIÊNCIAS HUMANAS - SEPECH \\ Humanidades, Estado e desafios didático-científicos \\ Londrina, 27 a 29 de julho de 2016}

proposta de Labov, com a Sociolinguística quantitativa, mostra que não há caos, mas sim variantes linguísticas que são condicionadas por fatores linguísticos e ou extralinguísticos e que essa variabilidade linguística segue regras variáveis de uso.

Nesse contexto, Labov entra com a "sociolinguística quantitativa, operando com números e tratamento estatístico" (TARALLO, 2005, p.8), para analisar a fala heterogênea de um grupo social ou comunidade.

A descrição da fala ocasionou problemas desde os estudos de Saussure, com oscilações e contradições. Labov, sabendo de toda essa variação, enumera quatro problemas que dificultam a descrição da língua a partir de dados coletados: a agramaticidade do discurso; a variação da fala; as dificuldades do registro; as limitações corpus.

Para estudarmos as variações, Labov (1972) propõe algumas definições pra se obter uma variável linguística: definir o número de variantes; estabelecer contextos e elaborar um índice quantitativo para medir os valores das variáveis. Além dessas variantes, Labov considera importante a idade, o sexo, a escolaridade, dimensão geográfica e nível socioeconômico dos entrevistados.

\section{VOGAIS MÉDIAS POSTÔNICAS FINAIS}

O sistema vocálico do português brasileiro (PB) apresenta acentuada variação, principalmente no contexto pretônico, e postônico. A respeito disso, Câmara Jr. mostranos a variedade de timbres das vogais átonas de sete fonemas $/ \mathrm{i}, \mathrm{u}, \mathrm{e}, \mathrm{o}, \mathcal{E}, \mathrm{o}, \mathrm{a} /$ que sofrendo neutralização vai para cinco, quatro e três, dividindo-se em pretônica, postônica não final e postônica final. Na posição pretônica, há perda da distinção entre vogais médias de primeiro grau /E/ e /o/ e nas vogais médias de segundo grau /e/ e /o/. No contexto brasileiro, tratando-se da vogal átona final, Câmara afirma que a ocorrência do processo de neutralização reduz o sistema vocálico para três vogais /i, u, a/ como nos exemplos fom[i] e ral[u].

Para Câmara Jr (1995, p. 39)

Em referência às vogais, a realidade da língua oral é muito mais complexa do que dá a entender o uso aparentemente simples e regular das cinco letras latinas vogais na escrita. O que há são sete fonemas vocálicos multiplicados em muitos alofones. Os falantes de língua espanhola têm, em regra, dificuldade de entender o português falado, apesar da grande semelhança entre as duas línguas, por causa dessa complexidade em contraste com a relativa simplicidade e consistência do sistema vocálico espanhol. Portugueses e brasileiros, ao contrário, acompanham razoavelmente bem o espanhol falado, porque se defrontam com um jogo de timbres vocálicos menor e menos variável que o seu próprio.

O referido estudioso, além de descrever as vogais em posição tônica, apresenta mais três quadros com as vogais em posição átona, onde ocorre a neutralização das mesmas. 


\section{SEMINÁRIO DE PESQUISA EM CIÊNCIAS HUMANAS - SEPECH \\ Humanidades, Estado e desafios didático-científicos \\ Londrina, 27 a 29 de julho de 2016}

\section{PRESSUPOSTOS METODOLÓGICOS}

O presente estudo foi realizado sobre o uso da vogal média anterior postônica final anterior (leite leiti) (gente $\sim$ genti) e pesquisada em duas localidades do Paraná: Londrina (quatro informantes com ensino fundamental) e Curitiba (quatro informantes com ensino fundamental e quatro com ensino superior). Esses informantes foram estratificados, pela equipe do ALIB, quanto à faixa etária (18 a 30 anos ou mais de 55), quanto ao sexo (feminino e masculino), quanto à região (Curitiba - capital e Londrina interior) e, na capital, quanto à escolaridade (ensino fundamental e ensino superior).

\subsection{Corpus analisado}

Os dados obtidos através das entrevistas, depois de transcritos e codificados foram analisados por meio do programa Goldvarb (2001),

Para a análise dos dados foram escolhidos como contextos as variáveis dependentes, se ocorre ou não a neutralização das vogais postônicas finais [e $\sim$ i] e [o u]. As variáveis independentes podem ser divididas em dois grupos: linguísticas e extralinguísticas.

As variáveis linguísticas foram escolhidas através da caracterização das palavras, classe gramatical: nome, verbo e advérbio; extensão silábica: monossílaba, dissílaba, trissílaba e polissílaba; a tonicidade do contexto precedente: átona e tônica; contexto precedente do ponto de articulação: bilabial, velar, alveolar, dental e palatal; modo de articulação: oclusivo, fricativo, nasal e tepe.

Quanto às variáveis extralinguísticas, analisamos o sexo (feminino e masculino), a faixa etária (18 a 35 anos e acima de 55), a escolaridade (ensino fundamental, e, em Curitiba, ensino superior), e as localidades (Curitiba e Londrina).

Para a composição do corpus deste estudo, recortamos por meio do programa Sound Forge as respostas dadas ao QFF que apresentavam as vogais postônicas finais [e] e [o]. Em seguida, esses dados foram codificados de acordo com as variáveis linguística e extralinguísticas previamente estipuladas pelo programa Goldvarb 2001.

\subsection{ALiB(Atlas Linguístico do Brasil)}

O projeto Atlas Linguístico do Brasil (Projeto AliB) tem como objetivo formar um atlas geral da Língua Portuguesa falada no Brasil. Para concretizá-lo, o projeto é composto por um grupo de pesquisadores do Instituto de Letras, envolvendo doze Universidades. É fundamentado por meio dos princípios gerais da geolinguística contemporânea, "priorizando a variação espacial ou diatópica e atento às implicações de natureza social que não se pode, no estudo da língua, deixar de considerar, com objetivos bem definidos e assim consubstanciados:" (Projeto Atlas Linguístico do Brasil - Comitê Nacional - 2013). 


\section{SEMINÁRIO DE PESQUISA EM CIÊNCIAS HUMANAS - SEPECH \\ Humanidades, Estado e desafios didático-científicos \\ Londrina, 27 a 29 de julho de 2016}

\section{VOGAIS MÉDIAS POSTÔNICAS FINAIS EM CURITIBA E LONDRINA}

Os contextos são apresentados conforme a ordem de relevância para aplicação da regra de alçamento. Primeiramente apresentamos os contextos linguísticos e em seguido os extralinguísticos, ou sociais, selecionados pelo programa Goldvarb (2001) como mais relevantes para o alçamento do [o].

\subsection{Vogal média posterior em posição de postônica final em Curitiba e em Londrina}

O primeiro contexto selecionado pelo programa Goldvarb(2001) como o mais relevante para a aplicação da regra de alçamento da vogal postônica final /o/ foi a extensão silábica.

\subsection{Contextos linguísticos}

De acordo com os resultados da extensão silábica na vogal postônica final [o], podemos observar que a ocorrência do $[\mathrm{u}]$ é maior quando se tem palavras trissílabas $(0,568)$, seguido pelas dissílabas $(0,464)$ e por último as polissílabas $(0,229)$. Conforme podemos observar, o contexto polissílaba é muito desfavorável à aplicação da regra de alçamento da vogal postônica /o/.

No contexto precedente do ponto de articulação na vogal postônica final [o], o contexto precedente palatal $(0,908)$ é muito favorável para que ocorra o alçamento do [o], seguido do contexto precedente velar $(0,526)$. Já o contexto alveolar $(0,177)$ é o mais desfavorável, pois praticamente inibe a ocorrência do alçamento do /o/ postônico.

Conforme os resultados apresentados no modo de articulação na vogal postônica final [o], podemos verificar que o modo de articulação mais favorável para o alçamento da vogal postônica final [o] é o modo fricativo $(0,875)$, seguido do nasal $(0,808)$. O mais desfavorável é o modo lateral $(0,302)$.

\subsection{Contextos extralinguísticos}

Segundo o resultado do alçamento do [o] postônico referente ao sexo, podemos constatar que o alçamento da vogal postônica [o], tem sua maior incidência no falar das informantes mulheres, já os homens parecem resistir ao alçamento do [o].

Quanto a faixa etária, são os jovens alçam mais a vogal [o] em posição postônica do que os idosos.

O último contexto extralinguístico selecionado pelo Goldvarb como relevante para aplicação da regra de alçamento do [o] foi a localidade. Podemos constatar que Londrina é muito favorável ao alçamento do [o], Curitiba, por sua vez, praticamente inibe a aplicação desta regra.

De modo geral podemos verificar que o alçamento da vogal postônica [o] nas duas localidades investigadas é governado pelos contextos linguísticos ponto linguístico palatal, modo de articulação fricativo e nasal e predomina na fala das mulheres jovens, principalmente moradoras de Londrina, localidade onde o alçamento é praticamente categórico $(0,919)$. 


\section{SEMINÁRIO DE PESQUISA EM CIÊNCIAS HUMANAS - SEPECH \\ Humanidades, Estado e desafios didático-científicos \\ Londrina, 27 a 29 de julho de 2016}

Diante desses resultados e apoiados em Labov (1972), que afirma sobre a variação e a mudança linguística que as mulheres procuram usar as formas mais conservadoras ou de prestígio e os jovens garantem vida longa a variante. Podemos dizer que o alçamento do [o] postônico final nas localidades investigadas não é estigmatizado, por prevalecer na fala das mulheres e caminha para uma mudança linguística em progresso por predominar na fala dos jovens.

\section{Londrina}

4.3 Vogal média anterior em posição postônica final em Curitiba e em

Em relação à vogal anterior postônica /e/, também, apresentaremos os contextos na ordem de relevância selecionada pelo programa de análise quantitativa Goldvarb (2001). O primeiro contexto selecionado para a aplicação da regra de alçamento da vogal anterior postônica /e/ foi a classe gramatical.

\subsection{Contextos linguísticos}

De acordo com a classe gramatical na vogal postônica final [e], podemos observar que a ocorrência do [i] é maior quando se tem verbos $(0,939)$, contexto quase categórico para a aplicação da regra de alçamento. Segundo Silva (2009), está classe não é a de maior fator para o alçamento no falar da cidade de Rincão Vermelho - RS, os numerais são os mais favoráveis.

Segundo os resultados, o modo de articulação mais relevante na vogal postônica final [e] é o modo nasal $(0,991)$, praticamente categórico, ou seja, neste contexto, quase sempre ocorre a vogal /e/ postônica final de forma alçada. Já os modos fricativo $(0,387)$ e oclusivo $(0,381)$ apresentaram-se muito desfavoráveis ao alçamento da referida vogal no contexto postônico.

Os resultados apontaram que a escolaridade mais relevante ao alçamento do [e] postônico é o ensino fundamental, ficando em segundo lugar o ensino superior.

$\mathrm{O}$ último contexto analisado foi localidade. A que mais alça a vogal postônica [e] é Londrina. Curitiba, por sua vez, praticamente inibe o alçamento dessa vogal.

De modo geral podemos verificar que o alçamento da vogal postônica [e] nas duas localidades investigadas é governado pela classe gramatical verbo, pelo modo de articulação nasal e fricativo que predomina na fala pessoas com o ensino fundamental, principalmente moradores de Londrina, localidade onde o alçamento é praticamente categórico $(0,963)$.

\section{CONSIDERAÇÕES FINAIS}

Através desses estudos, podemos concluir que o alçamento da vogal posterior [o] em posição postônica final, em Londrina, é bastante alto comparado à Curitiba. A vogal média anterior [e] em posição postônica final também tem um índice elevado na cidade de Londrina.

De acordo com os nossos objetivos pudemos observar, a partir dos resultados da análise, que o alçamento das vogais [e] e [o] deve-se tanto ao contexto linguístico quanto ao extralinguístico. 


\section{SEMINÁRIO DE PESQUISA EM CIÊNCIAS HUMANAS - SEPECH \\ Humanidades, Estado e desafios didático-científicos \\ Londrina, 27 a 29 de julho de 2016}

Quanto ao alçamento da vogal média anterior em posição postônica final [o], em Curitiba e em Londrina, tivemos como mais relevantes os contextos linguísticos: extensão silábica, sendo os vocábulos trissílabos mais favoráveis; no contexto precedente ponto de articulação, a palatal é o fator mais favorável para a ocorrência do $[\mathrm{u}]$, seguido do contexto velar. Os contextos extralinguísticos, as mulheres,os mais jovens e os informantes de Londrina favoreceram mais o uso alçado do /o/ postônico alçado.

Quanto aos resultados da vogal média anterior em posição postônica final em Curitiba e em Londrina, verificamos que seu alçamento está condicionado à classe gramatical dos verbos e ao modo de articulação nasal e ao contexto extralinguístico ensino fundamental e à localidade de Londrina.

De modo geral, podemos dizer que, apesar das limitações que quase todas as pesquisas apresentam, este estudo pode traçar os contextos linguísticos e extralinguísticos que governam o uso das vogais postônicas finais na capital paranaense (Curitiba) e em Londrina, localidade do Norte do Paraná. Acreditamos que ao acrescentarmos mais localidades e mais dados, teremos resultados ainda mais reveladores sobre o alçamento das vogais postônicas no falar paranaense. Salientamos também, que uma investigação mais aprofundada sobre a formação étnica dos habitantes destas localidades poderá ajudar na elucidação dos resultados, mas estas são propostas para novos estudos, visto que o tempo para a realização de um artigo é bastante curto e por isso limita muito a investigação.

\section{REFERÊNCIAS}

ATLAS LINGUÍSTICO BRASILEIRO. Disponível em: < http://twiki.ufba.br/twiki/bin/view/Alib/WebHome > . Acesso em: 11 agost. 2015

BAGNO, M. Nada na língua é por acaso: por uma pedagogia da variação linguística. 3. ed. São Paulo: Parábola Editorial, 2009.

BISOL, L. org. (1996) Introdução a estudos de fonologia do português brasileiro. Porto Alegre: EDIPUCRS.

\& BRESCANCINI, C. (org) (2002) Fonologia e variação: recortes do Português brasileiro. Porto Alegre: EDIPUCRS.

Neutralização das átonas. DELTA [online]. 2003, vol.19, n.2, pp. 267-276. ISSN 0102-4450.

CALLOU, D.; LEITE, Y. Iniciação à fonética e à fonologia. 10. ed. Rio de Janeiro: Jorge Zahar, 2005.

CÂMARA JUNIOR, J. M. Princípios de linguística geral. 4. ed. Rio de Janeiro: Acadêmica, 1964.

História e estrutura da língua portuguesa. Rio de Janeiro: Padrão, 1975. 


\section{SEMINÁRIO DE PESQUISA EM CIÊNCIAS HUMANAS - SEPECH \\ Humanidades, Estado e desafios didático-científicos \\ Londrina, 27 a 29 de julho de 2016}

Contribuição à estilística portuguesa. 3. ed. rev. Rio de Janeiro: Livro

Técnico; Brasília: INL, 1977.

. (1977) Para o estudo da fonêmica portuguesa. Rio de Janeiro: Padrão.

. Problemas de linguística descritiva. 11. ed. Rio de Janeiro: Vozes, 1984

Estrutura da língua portuguesa. 23 ed. Petrópolis: Vozes, 1995

CHAUI, Marilena. Convite à filosofia. 13.ed. São Paulo: Ática, 2009

CÓRDOBA, A. S. A neutralização das vogais postônicas finais no português uruguaio falado na cidade de Tranqueras - Uruguai. 2013. 87 f. Dissertação (Mestrado em Linguística Aplicada) - Universidade Católica de Pelotas, Pelotas. 2013.

FARACO. C. A. Linguística histórica. São Paulo: Ática, 1991.

FIORIN, J. L. (Org). Linguística? Que é isso? São Paulo: Contexto, 2013.

KAILER, D. A. Estudo da vogal pretônica média anterior em tempo real e em tempo aparente no falar rural de Guaraniaçu - PR. Estudos Lingüísticos, São Paulo, v. 31, p. $1-7,2003$.

LABOV, William (1972). Sociolinguistic Patterns. Philadelphia: University of Pennsylvania Press. [Padrões Sociolinguísticos. Trad.: Marcos Bagno; Marta Scherre e Caroline Cardoso. São Paulo: Parábola, 2008.]

LENZI, M. C.; BRENNER, T. M. Análise das vogais postônicas finais [e] e [o] nos falantes do município de Doutor Pedrinho. Work. pap. linguística., Florianópolis, v. 9, p. 55-62, jan. jun., 2008

MOLliCA, M. C.; MARTELOTTA, M. E. (Org.). Análises linguísticas: a contribuição de Alzira Macedo. Rio de Janeiro: UFRJ, 2000. p. 26-51.

MONTEIRO, J. L. Para compreender Labov. Petrópolis, RJ: Vozes, 2000.

OLIVEIRA E SILVA, G. M. Coleta de Dados. In: MOLLICA, M. C. Introdução à Sociolinguística Variacionista. Rio de Janeiro: Programa de Apoio à Produção de Material Didático (PROMADI 1)- UFRJ, 1992. p. 101-114. (Cadernos Didáticos UFRJ).

RODRIGUES, A. D. Mattoso Câmara e os estudos linguísticos no Brasil. Estudos da Lingua(gem), Vitória da Conquista, n. 2, p. 11-28, dez. 2005.

SANTOS, A. P. de. Vogais médias postônicas não finais na fala do estado do Rio de Janeiro. 2010. 162 f. Dissertação (Mestrado em Letras Vernáculas) - Universidade Federal do Rio de Janeiro, Rio de Janeiro. 2010. 
SILVA, S. M. da. Alçamento das vogais médias átonas finais no português falado em Rincão Vermelho-RS. Revista Língua \& Literatura, Rio Grande do Sul, v. 11, n. 17, p. 211-234, dez. 2009

TARALLO, F. L. A pesquisa sociolinguística. São Paulo: Ática, 2005. 7. ed

VIEIRA, M. J. B. (1994). Neutralização das vogais médias postônicas. Porto Alegre:UFRGS/ Instituto de Letras. Dissertação de Mestrado em Letras: Língua Portuguesa.

SILVA, R. O. Características acústicas e articulatórias das vogais postônicas na variedade do Português brasiliense. 2012. 151f. Dissertação (Mestrado em Linguística) - Universidade de Brasília, Brasília, 2012.

SILVA, T. C. Fonética e fonologia do Português: roteiro de estudos e guia de exercícios. 10. ed. São Paulo: Contexto, 2014. 